\title{
LA TRAGEDIA PRUEBA LA DEMOCRACIA. UNA REFLEXIÓN DESDE LAS SUPLICANTES DE ESQUILO Y DE EURÍPIDES
}

\author{
Alfonso FlóRez FlóRez* \\ doi:10.11144/Javeriana.uph31-63.tdse
}

\begin{abstract}
RESUMEN
La tragedia griega es expresión preferencial de los nuevos valores de la democracia ateniense en el siglo V. Tomando en cuenta esta convicción, se hace una lectura de las dos obras llamadas Suplicantes, la primera de Esquilo y la segunda de Eurípides, para examinar en qué sentidos la tragedia prueba la democracia cuando valores humanitarios fundamentales quedan en cuestión por la marginación de la sociedad de grupos de personas vulnerables.
\end{abstract}

Palabras clave: tragedia griega; filosofía griega; filosofía política; teorías de la democracia

\footnotetext{
${ }^{*}$ Pontificia Universidad Javeriana, Bogotá, Colombia.

Para citar este artículo: FLórez FlóREZ, A. (2014). La tragedia prueba la democracia. Una reflexión desde las Suplicantes de Esquilo y de Eurípides. Universitas Philosophica, 31(63), pp. 17-38, ISSN 0120-5323, ISSN en línea 2346-2426, doi: 10.11144/Javeriana. uph31-63.tdse
} 


\title{
DEMOCRACY GETS PROVED BY TRAGEDY. A READING OF AESCHYLUS' AND OF EURIPIDES' SUPPLIANTS
}

\author{
Alfonso FlóRez Flórez
}

\begin{abstract}
The new values of democracy in the Athens of the fifth century find in Greek tragedy a particularly apt way of expression. On this basis, by way of a close reading of both works called Suppliants, one by Aeschylus, the other by Euripides, it is intended to show in what sense can be said that tragedy is a test or proof for democracy. This test or proof occurs when fundamental human values are at stake by the social marginalization of groups of people particularly vulnerable.
\end{abstract}

Key words: greek tragedy; ancient greek philosophy; political philosophy; theories of democracy 


\section{Introducción}

LA TRAGEDIA GRIEGA HA SIDO CARACTERIZADA CON FRECUENCIA COmo un género propio de la democracia ateniense del siglo $\mathrm{V}^{1}$. Dentro de las muchas posibilidades para dotar de contenido a esta afirmación, se recurrirá a continuación a las dos obras de idéntico título de Esquilo y de Eurípides, las Suplicantes. A pesar de la diferencia de argumento, cada una de estas obras representa los conflictos a que se ve abocada una ciudad democrática ante la exigencia de amparo que le imponen grupos de individuos marginales y extranjeros. Que la obra de Esquilo pueda datarse hacia el año 460, mientras que la obra de Eurípides proviene del año 420, muestra a las claras que esta cuestión hizo presencia en la conciencia ateniense durante la mayor parte del siglo V, después de las Guerras Persas. Aquí, sin embargo, se dejarán de lado las cuestiones históricas, para examinar el asunto a partir de lo que la misma obra tiene que decir. Para ello se adopta el doble sentido que el verbo 'probar' tiene en español, es decir, como testimonio y como examen, de donde procede el extraño título de este artículo, quizás por una cierta anticipación de que cuando se trata de la democracia estos dos sentidos se corresponden y se reclaman uno a otro, es decir, que no cabe dar testimonio de la democracia sin que ella misma se someta a examen.

\section{Mujeres africanas negras en suelo europeo: las Suplicantes de Esquilo}

La escena De esta obra transcurre en las playas de la ciudad de Argos. Hasta allí han llegado desde Egipto el anciano Dánao y sus cincuenta hijas, que huyendo de un matrimonio que no quieren, suplican asilo al rey de la ciudad, Pelasgo. La voz del coro la conforman precisamente las mujeres, lo que da a sus peticiones, quejas y lamentos más urgencia y perentoriedad.

Ya desde el comienzo de la obra, el coro de mujeres presenta su situación:

Zarpamos de las bocas de finas arenas del Nilo, dejando al huir el país de Zeus, vecino de Siria, sin que el voto del pueblo nos hubiera impuesto pena de destierro por algún delito de sangre, sino impulsadas por aversión congénita hacia unos varones, porque renegábamos de la impía boda con los hijos de Egipto. (2-10)

\footnotetext{
${ }^{1}$ Cf. Chou (2012), Rhodes (2014).
} 
Las mujeres vienen huyendo de Egipto, no desterradas ni en razón de algún otro delito, sino porque se les ha impuesto un matrimonio que ellas rechazan. Presentar la reflexión, como hace un comentarista reciente, de que son oscuras las razones para que las mujeres rechacen el matrimonio ${ }^{2}$, equivale de algún modo a aliarse con sus perseguidores, como si la comprensión de la situación de las mujeres requiriera de una razón adicional al mero hecho de su manifestación del rechazo del matrimonio. La grandeza de Esquilo en este punto reside precisamente en entender y asumir que la expresión de las mujeres es suficiente razón para la decisión que han tomado de huir por mar desde Egipto: "iQue escapemos del lecho del varón -ihorror!, ¡horror!- sin boda e insumisas a su yugo!" (142-143).

"Haber arribado a tierra de Argos" se justifica, dice el coro, porque "nuestra estirpe se jacta de haberse iniciado al tacto y aliento de Zeus sobre aquella vaca que huía furiosa picada por el tábano" (15-18). Se trata de un aspecto que se desarrollará con largueza a lo largo de la obra, a saber, que a las mujeres asiste un cierto derecho para arribar a Argos dado que sus ancestros proceden de la ciudad. La joven Io, en efecto, era una doncella argiva, sacerdotisa del templo de Hera, a quien Zeus transformó en vaca para liberarla de los celos de Hera, y bajo esa forma, aguijoneada por el tábano que le envió la siempre suspicaz Hera, vagó por Grecia y Asia hasta asentarse en Egipto, donde dio a luz a un hijo de Zeus, Épafo (47), y recuperó su forma humana. Dánao, el padre de las mujeres, es un descendiente distante de Io. El tema, pues, de la consanguinidad cumple un papel en el recurso de asilo que invocan las mujeres, pero si bien no hay que desestimarlo, la problemática implicada tampoco se reduce a él, como se verá al considerar otros aspectos de la obra.

Así, aunque aducen raíces argivas, las mujeres se saben egipcias por varios motivos: el color de su piel: "Desgarro mi tierna mejilla tostada a orillas del Nilo" (70), "Raza de tez ennegrecida por los rayos del sol" (154155); su procedencia: "Me pregunto si habrá un defensor para mí en esta mi huida de la brumosa tierra de Egipto" (75-76); su idioma: "Tú entiendes bien, ¡oh tierra!, mi modo de hablar bárbaro" (118); su vestuario: "Una vez y otra rasgo mi velo de Sidón hecho de lino" (120-121), "Cinturones torcidos poseo que ciñen mis vestidos" (457).

\footnotetext{
${ }^{2}$ Bakewell, 2014, p. 69.
} 
Su padre aconseja a las mujeres que se acojan a la protección de los altares allí establecidos a los dioses, que exhiban los símbolos de su solicitud de asilo. "Contestad a nuestros huéspedes -les dice-con palabras respetuosas mezcladas con lamentos y expresiones que muestren la necesidad que os acosa, cual conviene a gente extranjera, y explicadles con toda claridad que esta huida vuestra no se debe a un delito de sangre" (193-196). Las mujeres deben hablar de modo comedido, con brevedad, en fin, le dice Dánao al líder del coro, "no olvides ceder -eres una pobre extranjera fugitiva-, que no está bien al débil andar con osadía" (202-203). En última instancia, las diferencias en las condiciones de género, de raza, de nacionalidad, de lengua y de cultura viene a resumirse en una condición de debilidad (héssonas, 203).

A su llegada al campamento, el rey de inmediato se da cuenta de que se halla en presencia de extranjeros: “¿De qué país es esa comitiva que no parece griega, fastuosa, con bárbaros vestidos y múltiples adornos, a quien estoy hablando?" (234-236). Manifiesta su extrañeza por el intempestivo arribo: "Es asombroso que os hayáis atrevido a llegar a este país intrépidamente, sin haberos hecho preceder de heraldos, representantes, ni guías" (238240). Como primera razón de su presencia allí, el corifeo declara que son de raza argiva. El rey no se muestra muy impresionado por las pretensiones genealógicas de las mujeres: "Difícil me resulta, oh extranjeras, creer lo que os oigo decir: que sois de nuestra estirpe argiva. Pues sois sobremanera parecidas a las mujeres libias y, en modo alguno, a las que aquí residen. Lo mismo podría el Nilo criar una tal planta; así mismo vuestro aspecto es semejante a los tipos chipriotas que forjan con forma femenina varones artesanos" (277-284). En otras palabras, el aspecto de las mujeres no es griego sino africano u oriental, y para el rey todas esas extranjeras -en el pasaje se nombran otras- son equivalentes, en el sentido de desconocidas en cuanto foráneas. Cuando ellas le explican que han llegado como suplicantes porque no quieren un matrimonio que les es impuesto, el rey les da una réplica típica de una sociedad masculina: "Así se acrecienta el poder entre los mortales" (338), en el sentido de que mediante la alianza matrimonial las familias se hacen más poderosas; pero el corifeo no se deja impresionar: "Es expediente fácil para desentenderse de los infortunados" (339), toda vez que el más fuerte podrá dado el caso repudiar al más débil, que como se ha visto son las mujeres. El rey de inmediato se da cuenta de que el costo de acceder a la solicitud de las mujeres es entrar en guerra, mas las mujeres reclaman que Justicia está de su lado (343). El rey se encuentra perplejo: “¡Ojalá que este asunto de hospedar a unos mitad ciudadanos, mitad extranjeros (astoxénon) 
no sea luctuoso, ni de lo inesperado e imprevisto se derive una guerra para nuestra ciudad! Porque nuestra ciudad no la necesita" (356-358) ${ }^{3}$. Tras la insistencia del coro que invoca a Justicia, la confusión del rey sale a la luz: "Mas no puedo ayudaros sin perjuicio, pero tampoco es prudente lo contrario, es decir, despreciar vuestras súplicas. Estoy lleno de dudas, y el corazón, de miedo, me atenaza de si obrar o no obrar, y hacer una elección de mi destino" (377-380).

El rey sabe que acoger a las suplicantes le traerá indecibles problemas, quizás hasta la guerra, pero tampoco ve viable despacharlas sin atender su pedido. En su desesperación vislumbra una salida honorable: ¿por qué las mujeres no apelan a la ley de su propio país? A fin de cuentas, tanto ellas como sus perseguidores son de Egipto (387-391). El coro responde con una nueva invocación a Justicia, dando a entender que las leyes de su país favorecen las pretensiones de los hombres y que ellas, como mujeres, carecen de espacio de maniobra frente a lo dispuesto por esas leyes: "Huir a las estrellas es el límite que me puse para evadir ese hostil matrimonio" (393$395)^{4}$. El rey no quiere servir de juez en una causa que no le atañe; además, en un caso delicado como este, no puede actuar a la espalda del pueblo, "ni siquiera teniendo el poder, no sea que algún día diga la gente, si por ventura algo no sucediera bien: 'Por honrar a extranjeras, causaste la perdición de la ciudad"” (399-401). ¿Piensa el rey, quizás, que dejando que la decisión la tome el pueblo, él saldrá indemne del trance? Sea de ello lo que fuere, aquí se ofrece uno de esos deliciosos anacronismos de la tragedia, en este caso un rey que teniendo el poder lo sujeta a la decisión popular. Con delicadeza, el coro le reprocha su pusilanimidad: “¿Por qué, si la balanza es equitativa, te arrepientes de hacerme justicia?” (404-405)' ; es decir, si en un platillo de la balanza de Zeus está la iniquidad y en el otro la justicia, ¿por qué las dudas para proceder? El rey ahora solo quiere acogerse a un pensamiento salvador: "¿No te parece que necesitamos un pensamiento salvador?" (417), esto es, un pensamiento que las salve a ellas, que salve a la ciudad y que lo salve a él.

Con una nueva admonición del coro, parece que el rey va esclareciendo su mente: "Ya lo tengo pensado" (438), proclama. No hay modo de evitar

\footnotetext{
${ }^{3}$ Traducción ligeramente modificada por el autor.

${ }^{4}$ Traducción ligeramente modificada por el autor.

${ }^{5}$ Traducción ligeramente modificada por el autor.
} 
la guerra, pero es que "sin dolor no existe salida en parte alguna" (442). Es como si el poeta hubiera tenido que venir en ayuda del rey, ya que esta es una idea esencialmente esquiliana ${ }^{6}$. Pero insólitamente, en una última y desesperada movida, el rey propone la realización de numerosos sacrificios, "remedio de cualquier calamidad" (451), como si buscando la ayuda divina, él no tuviera que proceder a tomar una difícil decisión. Desconcertadas, y puesto que no han obtenido una ayuda efectiva del rey, las mujeres declaran su última intención: tomar su propia vida. Ahora el rey se hunde en el mar de sus propias incertidumbres e indecisiones: "De múltiples modos, sucesos contra los que no puedo luchar y un sinfín de desgracias me inundan como un río; y ya he desembocado en un mar sin fondo de desdichas en extremo difícil de surcar” (468-470). ¡El mar que atravesaron las mujeres se ha convertido ahora en el mar de aflicciones del rey! Sin duda, el rey se sentiría en una posición más cómoda si no tuviera que tomar estos riesgos por un grupo precisamente de mujeres: “¡Manchar el suelo con sangre de varones por culpa de mujeres!" (477). El rey envía, entonces, a Dánao a la ciudad, tanto para que ofrezca sacrificios, como para que esté presente en la asamblea de los ciudadanos que aquel en persona se apresta a convocar. Como "la masa es amiga de censurar al jefe" (485), el rey estima que con la presencia de Dánao el pueblo tomará una decisión favorable a su propuesta, "pues todo el mundo está dispuesto a ser benévolo con los que son más débiles” (489).

Tras cumplir con lo dicho, Dánao regresa donde las mujeres con la buena noticia de que el pueblo ha tomado una decisión unánime a su favor. El decreto reza así: "Que libres habitemos esta tierra, sin consideración de gente prisionera, sino con el derecho humano del asilo; que nadie, ni habitante del país, ni tampoco extranjero, nos pueda reducir a servidumbre; $\mathrm{y}$, si alguien nos hiciera violencia, el ciudadano que no acuda en nuestra ayuda quede privado de derechos y sufra la pena de destierro por decreto del pueblo" (609-614)7. El padre aclara que la decisión se tomó gracias a la persuasiva presentación que el rey hizo de su caso, poniendo de presente los muchos males que aquejarían a la ciudad si no se acataban las disposiciones de Zeus protector del suplicante. De este admirable pasaje no se sabe qué admirar más, si el contenido del decreto o las razones de la decisión, pues el conjunto se constituye en espíritu de piedad y de respeto a valores supremos,

\footnotetext{
"Véase el célebre pasaje del Agamenón, 177: "páthei máthos", "aprender por el sufrimiento".

${ }^{7}$ Traducción ligeramente modificada por el autor.
} 
lejos ahora de todo cálculo sobre beneficios particulares. Por lo demás, como lo muestra el consumado arte del poeta, una decisión que afecta a toda la comunidad no puede tomarse sino en el seno de la asamblea democrática, a la que se llega en medio de todo tipo de dudas e inquietudes del gobernante, que sólo poco a poco va aclarando su juicio.

En el entretanto comienza a llegar la avanzada de los egipcios, que con violencia se proponen tomar a las mujeres. En esas retorna el rey, que increpa duramente al heraldo egipcio, invocando el decreto que el pueblo acaba de tomar (942-949). Como lo muestra el poeta, el decreto es algo concreto que empieza a tener efectos de inmediato, y para su honra, el rey lo acoge sin dudar, así con ello se esté corriendo el riesgo de una guerra. Los egipcios se retiran por ahora, no sin declararle la guerra a la ciudad ${ }^{8}$. Las mujeres, ya libres de la amenaza de sus perseguidores, invocan todas las bendiciones sobre la tierra argiva, a la vez que su padre no deja de hacerles una última exhortación, ahora que sus súplicas han sido acogidas: "A un grupo de gente desconocida sólo se la aprecia algo cuando pasa el tiempo; y contra el meteco todos tienen presta una mala lengua, y es cosa que cae bien decir de algún modo algo que lo manche. ¡Os exhorto a que no me llenéis de vergüenza!" (995-999). Es decir, que en su nueva tierra las suplicantes deben poner especial empeño por obrar con prudencia y discreción, sabiendo que muchos las miran, no todos para bien, y muchos buscarán también la ocasión para dañar su nombre. En el campo jurídico y político si bien hay que saber preparar una decisión, esta se toma en un momento y sus efectos son así mismo inmediatos; en el campo social y cultural, sin embargo, la decisión toma tiempo en surtir efecto y no deja de tener enemigos o al menos contradictores, por lo que las actuaciones particulares de los extranjeros acogidos deben llevarse con el mayor cuidado.

\section{El débil impío e injusto: las Suplicantes de Eurípides}

La escena de esta obra transcurRe en Eleusis, cerca de Atenas. Después de la fracasada expedición de los Siete contra Tebas, el rey de esta ciudad,

\footnotetext{
${ }^{8}$ Las otras dos obras de la trilogía a la que pertenecen las Suplicantes, los Egipcios y las Danaides, se han perdido y la reconstrucción de la secuencia completa es incierta. Cf. The beginning and the end of Aeschylus' Danaid trilogy, en Sommerstein (2010, pp. 89-117) y Bakewell (2014, pp. 70s). En cualquier hipótesis, el asilo que la ciudad de Argos les ha otorgado a las Danaides resultará en un infortunio para la ciudad y para su rey.
} 
Creonte, ha prohibido que los cadáveres de los atacantes reciban las honras fúnebres, en especial, los generales que lideraron la expedición. Al santuario de Deméter en Eleusis han llegado las madres de estos siete generales para suplicarle al rey de Atenas, Teseo, su intercesión en este asunto. La madre de Teseo, la reina Etra, se ha unido a la voz de las suplicantes, así como Adrasto, el rey de Argos, que comandó la fallida empresa. La voz del coro la conforman las mujeres, pero hacia el final interviene también un coro de niños, los hijos de los caídos ante Tebas, futuros Epígonos.

La reina Etra presenta la situación con estas palabras:

Estas sus madres quieren enterrar los cadáveres de los que murieron en el combate, pero los que ahora mandan tratan de impedírselo y ni siquiera quieren acceder a que se los lleven, conculcando con ello las leyes divinas. Y aquí está Adrasto mismo como suplicante, soportando lo mismo que ellas la carga de pedirme auxilio. Sus ojos están húmedos por el llanto y lamenta la guerra y la maldita expedición que él mismo sacó de su patria. Él es quien me apremia a persuadir con súplicas a mi hijo a que se convierta en protector de los cadáveres, ya sea por la razón o por la fuerza de las armas; a que se convierta en copartícipe de su entierro echando sobre mi hijo solo y sobre la ciudad de Atenas esta carga. (16-28)

La situación, entonces, consiste en que hay una parte fuerte que subyuga a una parte débil, negándole incluso que cumpla con los oficios sagrados de honrar a sus muertos. El asunto se complica porque los difuntos fallecieron en un ataque a la ciudad que ahora prohíbe su entierro. Las suplicantes, con el rey de la fracasada expedición a la cabeza, se han acercado a la reina Etra, madre de Teseo, para que intervenga a su favor. Atenas no ha participado en el conflicto entre Argos y Tebas, pero al tratarse de un acto de piedad, reconocido por todas las ciudades griegas, los suplicantes juzgan que Atenas bien puede mediar en este impase, sea con la razón o con las armas. Teseo no ha pronunciado una palabra, ni siquiera está enterado del asunto, y ya se halla en medio de un problema de difícil solución.

Como es apenas evidente, Teseo acude alarmado al llamado de su madre y la encuentra rodeada de los suplicantes. Etra le da la palabra a Adrasto para que le presente a Teseo las razones de sus súplicas. Interrogado por Teseo, Adrasto le expone la cadena de acontecimientos que ha conducido al funesto resultado. A Teseo le queda claro que Adrasto y sus hombres obraron de modo imprudente e impío al atacar a Tebas. Pregunta Teseo: 
-¿Consultaste a algún adivino y observaste el fuego de las víctimas?

-¡Ay! -exclama Adrasto-, me estás atacando precisamente por donde me equivoqué.

-¡Conque no viniste, a lo que parece, con el beneplácito de los dioses!

-Y lo que es más, vine contra el parecer de Anfiarao.

-¿Así tan a la ligera diste la espalda a los dioses?

-Es que me asustó la violencia de los dos jóvenes.

-Seguiste tus impulsos en vez tu razón -concluye Teseo-. $(155-161)^{9}$

De este intercambio dialogal a Teseo le va quedando claro que el ataque a Tebas no se dio por razones de justicia ni contando con el favor de los dioses, sino precisamente todo lo contrario, desoyendo los oráculos e impulsados más por un ardor militar (eupsukhían) que por la razón (euboulías). ¡Quienes no respetaron los preceptos de piedad recurren ahora a ellos para intentar subsanar los aciagos resultados de su primera decisión!

Teseo, que es joven y animoso, sabe que bajo su mando ilustrado y piadoso Atenas nunca se habría dejado llevar a una situación tal. Le pone de presente a Adrasto que él no supo o no quiso dejarse guiar por la esclarecida razón:

¿No es cierto que somos caprichosos cuando dios nos ha dado tales armas para nuestra asistencia y nos parecen insuficientes? Es que nuestra mente anda buscando ser más poderosa que dios y por tener arrogancia (gaûron) nos creemos más sabios que los inmortales. También tú -increpa a Adrastoperteneces a esa clase (...) Arrastraste a la guerra a los argivos, a pesar de las predicciones de los adivinos; deshonraste a los dioses conculcando sus leyes con violencia y arruinaste tu ciudad. (214-219; 229-231)

En medio de su discurso, Teseo entrevé razones para sustraerse de la incómoda súplica que se le ha presentado:

Entonces, ¿cómo voy a ser tu aliado? ¿Qué razón válida daré a mis ciudadanos? ¡Vete en paz! Si no has tomado una buena decisión, carga la culpa a tu mala fortuna y déjanos en paz. (246-249)

\footnotetext{
${ }^{9}$ La ciudad de Argos va a verse involucrada en el ataque a Tebas cuando uno de los regentes de Tebas, Polinices, expulsado por su hermano, Eteocles -los dos hijos del malhadado Edipo-, se allegue en compañía de Tideo, también desterrado de su ciudad, donde el rey de Argos, Adrasto, para convencerlo de montar la expedición de los Siete contra Tebas. Estos son los dos jóvenes de cuya violencia se queja Adrasto. Anfiarao, que terminará siendo uno de los Siete, es un reputado vidente y general, primo y cuñado de Adrasto.
} 
Teseo ha encontrado una salida digna, con el añadido de que el nombre de Atenas ha quedado en limpio, pues da a entender que si la causa fuera justa, él estaría dispuesto a intervenir. Habiendo mediado, empero, en la acción guerrera de los argivos la imprevisión, la arrogancia, la impiedad, él se siente eximido con justicia de mezclarse en ese asunto. Siendo la cabeza del gobierno, no puede ir donde sus ciudadanos para que por una causa injusta aprueben una intervención que posiblemente signifique la guerra.

Teseo no está preparado, sin embargo, para la respuesta que Adrasto le da a su discurso. Le dice el derrotado rey:

No te hemos elegido como juez de nuestros males. Hemos venido a ti, soberano, como médico de ellos; tampoco como acusador ni verdugo -aunque se pruebe que he obrado mal-, sino para buscar ayuda. Si no quieres dármela, será fuerza que me contente con tu decisión. ¿Qué puedo hacer? (253-257)

En estas palabras sublimes, Adrasto expresa con dignidad la súplica del débil de todas las épocas. Es posible, sí, que sea por sus propias decisiones, erróneas, faltas de juicio, impías incluso, que alguien se ha puesto en una situación de vulnerabilidad extrema, donde implora la ayuda de un poderoso que le permita seguir adelante. Quien se encuentra en esa circunstancia solicita un auxilio sin condición. Lo que menos necesita ahora es que se lo lleve a un tribunal para juzgarlo, acusarlo y ejecutarlo. Si quien está en la posición de poderle brindar ayuda no quiere hacerlo, que no lo haga, pero que tampoco busque justificar su decisión echándole en cara al débil sus faltas pasadas ${ }^{10}$.

Adrasto se dispone a marcharse, pero el corifeo hace una última invocación a Teseo. Le pone de presente que los argivos y los atenienses comparten los mismos ancestros, pero, más importante que ello, invoca la común condición humana:

El animal tiene como refugio una cueva, el esclavo los altares de los dioses y un Estado busca cobijo en otro Estado cuando hay tempestad. De las cosas humanas, ninguna es posible que sea feliz por completo. (267-270)

\footnotetext{
${ }^{10}$ De allí la inaceptable interpretación de quienes ven esta obra luminosa en sombríos tintes de matices de gris; véase Storey, 2014, p. 468.
} 
Teseo, le recuerda el corifeo, como humano que es, está expuesto así mismo a la variabilidad de las cosas humanas. Es en este sentido que el recurso a un ancestro común toma toda su fuerza. Por su misma participación en lo humano, los hombres deben ayudarse entre sí. Teseo vacila, pero entonces la intervención de la reina Etra se muestra decisiva. La reina le pone de presente a su hijo que no deshonre las leyes divinas, es decir, le pide a Teseo que escuche lo que los dioses tienen que decir en este momento. Además, quienes constriñen a los suplicantes están obrando en contra de las tradiciones de todos los griegos. Por último, Teseo tiene el poder para obrar, de modo que si no lo hace será por cobardía. "Hijo -concluye-, ¿no vas a prestar ayuda a los cadáveres y a estas afligidas mujeres que te necesitan?" (326-327). A las palabras de la madre, quizás por provenir de ella, Teseo ya no va a oponer más argumentos, si bien deja de presente la razonabilidad de lo que ha dicho respecto de Adrasto y sus compañeros:

Madre, mis palabras anteriores tienen razón para con éste. Le he manifestado en qué decisiones creo que ha errado, pero también veo las razones con las que me reprendes. Veo que no es propio de mi carácter huir del peligro. Pues, por realizar muchas hazañas, he cosechado entre los griegos la fama de ser azote permanente de los malvados. Así que no es posible que me niegue al esfuerzo. (334-342)

Las razones por las que Teseo se decide a obrar quizás no sean las que esperaban las suplicantes, pues, ya que tiene el poder y el nombre para hacerlo, Teseo reacciona más ante el adversario que impone una medida injusta que por estar a favor de la solicitud de humanidad de los suplicantes. Este movimiento puede interpretarse como si el poeta quisiera dejar claro cuáles son los límites de la acción política en conflictos humanitarios. Queda preparada así la siguiente escena, que se desenvolverá en el plano netamente político.

Teseo anuncia su decisión:

Lo haré, voy a tratar de liberar los cadáveres con la persuasión de mi palabra; pero si no es posible, lo llevaré a cabo con la violencia de la lanza y sin la envidia de los dioses. (346-348)

Como la decisión implica un riesgo de guerra, el gobernante va a consultar al pueblo: 
Quiero que todo el pueblo adopte esta decisión. La adoptará si yo lo deseo, pero si les comunico mi palabra tendré al pueblo mejor dispuesto. Pues yo lo he convertido en soberano liberando este Estado, dándole sufragio igualitario. $(349-353)^{11}$

El consciente anacronismo de la tragedia en asuntos políticos lleva a Teseo a presentarse como soberano querido y respetado por su pueblo, que lo seguirá en cualquier decisión que él tome, pero como gobernante Teseo pretende más que la mera obediencia del pueblo, quiere su buena voluntad (eumenésteron), para lo cual le va a comunicar a la asamblea su palabra, esto es, va a presentarle sus razones (tô̂ lógou prosdoús). Se trata, en efecto -aquí se habla de Atenas frente a Atenas-, de un pueblo soberano, donde la libertad va de la mano del sufragio. Lo interesante es que mientras la discusión se mantuvo en el plano de los principios, Teseo no pensó en recurrir al pueblo; solamente una vez que ha tomado la decisión en el orden político de confrontar a un gobierno injusto, Teseo apela a la voluntad popular.

El rey dispone enseguida todos los preparativos, tanto para la paz, como para la guerra. Para el primer caso, enviará un heraldo a Creonte "con el ruego de que devuelva los cadáveres" (358); para el segundo, después de la asamblea y el voto favorable de los ciudadanos, reunirá un contingente militar. En esas está cuando arriba un mensajero tebano. El intercambio que sigue entre Teseo y el heraldo es una muestra preciosa de debate político entre democracia y tiranía, tanto más cuanto que Teseo mismo no deja de acusar ciertos rasgos absolutistas.

“¿Quién es el tirano de esta tierra?" (399), pregunta el heraldo, a lo que Teseo ofrece una réplica muy ateniense: "Extranjero, para empezar, te equivocas al buscar aquí a un tirano. A esta ciudad no la manda un solo hombre, es libre" (403-405). Y le da una brevísima descripción del funcionamiento de la democracia: "El pueblo es soberano mediante magistraturas anuales alternas y no concede el poder a la riqueza, sino que también el pobre tiene igualdad de derechos" (406-408). Como se sabe, en Atenas el ejercicio de los cargos públicos se asigna por sorteo, con lo que todos los ciudadanos tienen no solo la posibilidad de participar en el gobierno de la ciudad, sino también la obligación de hacerlo ${ }^{12}$. El heraldo

\footnotetext{
${ }^{11}$ Traducción ligeramente modificada por el autor.

${ }^{12}$ Cf. Martin, 2000, pp. 87s.
} 
estima que este sistema tiene una desventaja fundamental. Dice: La ciudad de la que vengo la domina un solo hombre, no la plebe. No es posible que la tuerza aquí y allá, para su propio provecho, cualquier político que la deje boquiabierta con sus palabras. Al pronto se muestra blando y le concede cualquier gracia, pero enseguida la perjudica y, con inventadas patrañas, le oculta sus pasados errores y consigue escapar de la justicia. Y es que, ¿cómo es posible que un pueblo, que no es capaz de hablar a derechas, pueda llevar derecha a su ciudad? (410-418). Teseo no deja de admirar el ingenio del heraldo y se adentra en la discusión. Le responde entonces: Nada hay más enemigo de un Estado que el tirano, pues, para empezar, no existen leyes de la comunidad y domina solo uno que tiene la ley bajo su arbitrio. Y esto no es igualitario. Cuando las leyes están escritas, tanto el pobre como el rico tienen una justicia igualitaria. El débil puede contestar al poderoso con las mismas palabras si lo insulta; vence el inferior al superior si tiene a su lado la justicia. La libertad consiste en esta frase: '¿Quién quiere proponer al pueblo una decisión útil para la comunidad?’. El que quiere hacerlo se lleva la gloria, el que no, se calla. ¿Qué puede ser más democrático que esto para una comunidad? Es más, cuando el pueblo es soberano del país, se complace con los ciudadanos jóvenes que forman su base; en cambio, un rey considera esto odioso y elimina a los mejores y a quienes cree sensatos por miedo a perder su tiranía. (429-446)

Como se ve, el heraldo asume que la ciudad dirigida por un solo hombre está en mejor posición tanto de fijar sus metas, como de alcanzarlas, a la vez que critica que ciudadanos rústicos y del común puedan conducir los asuntos del Estado sin tener un verdadero conocimiento de lo público y sin poder tampoco anteponer el interés general a sus intereses particulares. $\mathrm{Si}$ el gobierno depende de la voz en las asambleas y la justicia de la voz en los tribunales, es de temer que sea la elocuencia interesada la que termine apropiándose de los asuntos del Estado, con el agravante de resultar impune en todo ello. Por su parte, Teseo expone que la mayor debilidad de la tiranía es el propio tirano, pues dispone de las leyes a su antojo y en su provecho personal. La democracia es ante todo democracia ante la ley, y ante la ley escrita; siendo iguales, todos los ciudadanos tienen el mismo derecho de acceso a la justicia, con independencia del monto de sus bienes o de su estatus social. En orden al gobierno, solo cuentan las buenas ideas que vayan en beneficio de la comunidad; estas ideas se debaten y se someten a aprobación en la asamblea, que es seguramente más de lo que puede lograr un solo tirano, por ilustrado que sea. Teseo señala como último punto que es 
propio de la democracia la renovación de las generaciones, con lo que todos van cuidando de lo común de la ciudad, mientras que en su abrazo del poder los tiranos eliminan toda renovación de la comunidad, que se ve privada así de nuevas ideas y nuevas fuerzas para su prosperidad. A partir de este intercambio parece seguirse que gracias a sus procedimientos de discusión y de decisión entre iguales, la democracia ofrece el espacio más adecuado para darle una resolución correcta al conflicto que enfrenta a argivos y tebanos, mientras que la decisión que ha tomado el tirano no responde sino a sus intereses privados, de afirmación vacua de su poder con recurso a la venganza y la ignominia. Empero, el cruce de opiniones entre Teseo y el heraldo todavía no ha llegado a su fin.

En efecto, al terminar su discurso Teseo le echa en cara al heraldo el no haberse sabido mantener en su estricta función de mensajero. Este, sin dejarse amedrentar, le responde: "De lo disputado puede que esta sea tu opinión, que la mía es la opuesta" (465-466), y procede a proclamar la decisión de Creonte de no entregar los cadáveres, ni a los argivos, ni a los atenienses. El heraldo añade de su cuenta una exhortación a la reflexión y a la paz, y le recuerda, como para mortificar a Teseo, que el ataque argivo fue producto de la insolencia, mientras que la muerte de los atacantes corresponde a un acto de justicia. Teseo, sin responder a la provocación, le contesta con calma al heraldo que las honras fúnebres son un acto de justicia con el que se salvaguarda la ley de todos los griegos. Si Tebas recibió daño de los atacantes argivos, estos ya están muertos. Le dice: "Habéis rechazado al enemigo con honor para vosotros y vergüenza para ellos. La justicia se ha cumplido. Dejad ya que la tierra cubra a los muertos" (529-531) ${ }^{13}$. Y adopta el argumento que le dio el corifeo, que casi lo persuade en ese momento: "Insensatos, ya conocéis las miserias humanas; nuestra vida es lucha. Unos hombres tienen éxito más pronto, otros más tarde y otros en el momento (...) Es preciso, pues, saber esto para no dejarse llevar por la ira si se recibe una pequeña injuria y no delinquir en cosas que dañen a toda la comunidad" (549-551, 555-557). Con un último intercambio de amenazas mutuas, el heraldo se marcha.

Esta segunda parte de la discusión entre Teseo y el heraldo abandona el terreno de lo político y vuelve al de los principios, donde Teseo había

\footnotetext{
${ }^{13}$ Traducción ligeramente modificada por el autor.
} 
vacilado de modo que no alcanzó la completa persuasión sino con el discurso de su madre Etra y el recurso que ella ante puso ante sus ojos del poder político. Del discurso de Etra, en este momento Teseo retoma, sin embargo, la referencia al carácter vinculante de las costumbres panhelénicas, mientras que de la intervención del corifeo adopta las razones sobre el carácter variable de las cosas humanas, que ya sube a unos, ya sube a otros, con lo que no hay que ensoberbecerse por pequeñas y particulares rencillas.

En suma, si en un primer momento Teseo quiso dejar de lado las consideraciones de principio y tomó un curso de acción determinado por intereses políticos, ahora, ante la incisiva intervención del heraldo, hace explícitos los principios de la democracia y su superioridad frente a la tiranía y da a entender que la decisión adoptada dimana de dicha superioridad de la democracia. El heraldo no queda persuadido y lleva la discusión al terreno de los principios, en este caso, la justicia que violaron los argivos, en el entendido de que el haber atacado a su propia ciudad justifica que Polinices quede sin entierro y con él sus aliados. Ahora Teseo ya no puede vacilar más y le argumenta al heraldo a partir de principios de humanidad universal y de piedad que en un primer momento no habían tenido en él plena fuerza de convicción. Es posible ver en este cambio de posición un aprendizaje del joven e impetuoso Teseo, pero más allá de este motivo psicológico hay que discriminar lo que parece ser la posición del poeta: los principios universales no son negociables ni discutibles y tienen validez universal, pero su aplicación requiere de compromisos políticos explícitos cuya adopción sólo la democracia hace posible.

Una vez se precisan las razones del curso de acción adoptado, el argumento se desenvuelve con rapidez. Creonte no acepta la propuesta de Teseo, por lo que a este no le queda más opción que el recurso de las armas. En un combate encarnizado y con muchos muertos, Teseo logra el rescate de los cuerpos de los generales argivos y los conduce a Eleusis para ofrecerles las honras funerarias. Para el caso en cuestión no se requiere la exposición detenida de las escenas finales del drama, como el discurso fúnebre de Adrasto donde elogia la memoria de los caídos, el suicidio de la viuda de uno de los capitanes, que se lanza a la pira funeraria de su marido, y la aparición de Atenea que establece un pacto de honor entre Argos y Atenas. 


\section{Humanidad y democracia}

EN CONFORMIDAD CON LO ANUNCIADO EN LA INTRODUCCIÓN, corresponde mostrar en qué sentido la tragedia prueba la democracia. Hay que hacer notar primero que a pesar de todas las diferencias dramatúrgicas y también posiblemente de contenido, los dos poetas concuerdan en lo fundamental. Casi con seguridad no pudo deberse a una mera casualidad que Eurípides hubiera adoptado para su obra el mismo título que Esquilo le había dado a la suya. La temática es la misma y si bien el proceder euripidiano es más detenido y detallado, las etapas que recorren las dos obras son equiparables. Esto, por supuesto, ya no obedece a la casualidad sino a la preclara comprensión que el poeta tiene del problema planteado.

Si bien la figura del suplicante tiene arraigo tradicional en Grecia, los dos poetas la exponen de modo tal que la llevan a los límites de lo admisible en la cultura griega y en cualquier cultura. Esquilo conforma la figura del suplicante con todas las notas de la diferencia: mujer, extranjera y negra, además de numerosas, pues no se trata de una sola persona. En Eurípides los suplicantes piden ayuda para quienes irrespetaron las leyes divinas y humanas. Las madres de los caídos son las suplicantes, pero la presencia del rey muestra que, en cierto sentido, los muertos mismos también suplican. Quienes quebrantaron las leyes y ya recibieron un castigo justo por ello no tienen otro recurso ahora que la súplica. De este modo los poetas muestran que el auténtico suplicante es aquél que se sustrae en verdad a todas las normas establecidas por la sociedad a la que se acoge. Se suplica el refugio o la ayuda precisamente cuando los recursos ordinarios han fallado, y han fallado porque el suplicante se halla en una situación de debilidad extrema que lo pone al margen de las vías ordinarias de resolución de las cuestiones concernientes a la esencia de lo humano, una vida y una muerte dignas.

Ahora bien, el gobernante -el rey de Argos, Pelasgo, y el rey de Atenas, Teseo, respectivamente-, acostumbrado como está a gobernar, esto es a regir a su pueblo mediante decisiones de índole política, no se halla preparado para afrontar la situación que le presenta la presencia de suplicantes en su territorio. Es así como en un primer momento el gobernante tiene la pretensión de darle una solución meramente política al asunto. En Esquilo esta solución pasa por no querer reconocer el rey Pelasgo el común ancestro que vincula a las suplicantes a la ciudad de Argos, para luego desestimar su 
rechazo del matrimonio como una razón válida para otorgarles asilo. El poeta da a entender que el rey reconocerá a regañadientes el ascendiente común de las mujeres, sin que deje de considerarlas como extranjeras. Es importante hacer notar que aunque en las dos obras se aduce un parentesco entre quienes suplican y aquellos a quienes se suplica como razón para recibir la protección pedida, en ninguno de los dos casos este motivo será determinante para el curso de acción que se va a tomar. Se trata, más bien, de poner de presente la común condición humana, aspecto borrosamente presente en Esquilo bajo el epíteto de astoxénon, ciudadano y extranjero, que en Eurípides ya adquiere un perfil propio en las palabras que el corifeo le dirige a Teseo. Como siguiente movimiento en su comprensión política del asunto, el rey argivo quiere remitir la petición de las mujeres a la justicia del propio país del que ellas provienen. Cuando ellas rechazan esta idea, el soberano, medio convencido, medio escéptico, siempre dubitativo, propone la realización de sacrificios, quizás con la esperanza de que las entrañas de las víctimas o el humo de la grasa quemada o alguna otra circunstancia pueda interpretarse en sentido favorable para sus intereses de no actuar y no comprometerse. Las mujeres comprenden que por esta vía su caso simplemente va a ser desestimado, por lo que adoptan la única y última resolución que les queda, tomar su propia vida. El rey se queda sin opciones políticas, pues, piadoso como es, no va a permitir que el suelo de la ciudad se mancille con un acto atroz como ese.

En el caso Eurípides, el gobernante busca enterarse de todos los detalles pertinentes del caso, tras lo cual declara satisfecho que se trata de un asunto que no le corresponde, toda vez que los suplicantes violaron principios humanos y divinos en el conjunto de acciones que los condujeron a la lastimosa condición de suplicantes. Por ello se siente eximido de prestarles su ayuda. Cuando los suplicantes le plantean condiciones de humanidad, con independencia de cómo hayan llegado a la situación en que se encuentran y apelando a la común condición humana, Teseo duda, pero se mantiene en su primera decisión. Entonces se da la intervención de su madre, la reina Etra, que le pone de presente la superior posición política que el propio Teseo ha ganado en el mundo helénico y que esta es una ocasión propicia para que muestre su verdadera valía en este orden. Teseo accede, entonces, a intervenir a favor de los suplicantes, mas no por razones de humanidad, pues sigue desestimando la causa de los suplicantes como tal, sino por motivos de conveniencia política. 
A continuación y porque en ambos casos la decisión que los dos reyes han tomado implica un riesgo de guerra, los gobernantes consultan a la asamblea democrática de su ciudad, no de un modo neutral sino adoptando una posición activa de defensa de la causa propuesta. Es claro que en este punto la acción en la obra esquiliana se halla un paso más adelante que la de la obra euripidiana ${ }^{14}$. En efecto, en Pelasgo confluyen los motivos políticos con los humanitarios - como él mismo dice, el río desemboca en el mar-, por lo que no cabe establecer una diferenciación fáctica entre unos y otros, si bien la consulta al pueblo se desarrolla en el ámbito de los principios, como lo muestra el contenido del decreto emitido por la asamblea, donde se establecen los principios de libertad, autonomía y protección para los suplicantes, con duras penas para el ciudadano que no los cumpla. Por el contrario, Teseo consulta a la asamblea acerca de la decisión política que él ya ha tomado de rescatar los cuerpos, obtiene el voto favorable y unánime del pueblo, pero dado que esta consulta versa sobre una decisión política, la asamblea no emite ningún decreto donde se presenten los compromisos de índole humanitaria con los que la ciudad se compromete. Eurípides ha querido que esta discusión se dé sobre el escenario en el intercambio entre el heraldo y Teseo.

La discusión entre tiranía y democracia se desarrolla en dos momentos. Primero, el heraldo le pone de presente al rey las ventajas administrativas de que goza una ciudad regida por un tirano; Teseo no lo niega, pero le hace caer en cuenta al heraldo que el costo de dicha eficiencia práctica es la negación de la justicia, que debe ser equitativa, pero que en una tiranía favorece, en cambio, al tirano, en desmedro del resto de ciudadanos. Por lo demás, la administración puede conducirse de un modo satisfactorio en una democracia con medidas que cualquier ciudadano puede proponer con el fin de mejorar la vida en común. Sin ceder, el heraldo aplica, en un segundo momento, precisamente la noción de tiranía dentro de la que se mueve su pensamiento. Le indica a Teseo que los atacantes violaron principios humanos

\footnotetext{
${ }^{14}$ La acción en Esquilo es más pausada porque el autor dispone de tres obras para desarrollar los diferentes momentos del conflicto, mientras que en Eurípides, donde las obras de la trilogía ya no están conectadas entre sí, se debe apurar el desarrollo de la acción. Nótese que al ser más pausada la acción en Esquilo, cuando se da la consulta a la asamblea se está mucho más adelante, no más atrás, en el desarrollo de la tragedia particular; en Eurípides, se está más atrás, pues sólo dispone del espacio de esta obra para llevarla a su resolución.
} 
y divinos por lo que el castigo a que se los somete es justo. Con ello el heraldo manifiesta la parcialidad de la tiranía en la aplicación de la ley. Teseo lo hace caer en cuenta de este error, enfatizando que quien ha muerto ya ha pagado cualquier culpa en la que hubiera incurrido, por lo que el respeto a los difuntos constituye un principio inviolable. Con esta argumentación Teseo se aclara a sí mismo que las razones para la decisión que ha tomado no son solo ni principalmente políticas; son razones de principio, donde la defensa de lo justo no es negociable. Si la democracia consiste en la afirmación universal de la justicia, la defensa de los cuerpos de los caídos viene a equivaler a la defensa del sistema democrático. Solo una vez que la comprensión de su actuar se ha elevado al nivel de los principios puede Teseo entrar en combate.

Una última anotación sobre la relación de las dos obras permite entender que la tragedia esquiliana se sitúa en un momento mítico anterior a la euripidiana, puesto que Dánao opera la refundación de la ciudadela de Argos, donde varias generaciones después reina Adrasto, el jefe de la expedición contra Tebas. Esto indica que, en cierto sentido, Argos recibe ayuda de Atenas en una causa humanitaria cuando la propia ciudad, en un evento casi fundacional, había prestado su ayuda a las Danaides en una causa también humanitaria. De este modo, los compromisos con los principios operan no sólo en el orden horizontal sino también en el orden vertical. Las dimensiones sincrónica y diacrónica conforman así el tejido de una humanidad que se halla ineluctablemente vinculada consigo misma tanto en el orden contemporáneo como en el orden genealógico. De allí que el compromiso con las causas humanitarias desborde el estrecho margen del cálculo político al que alguien podría estar tentado a reducirlas.

\section{Conclusión}

CON ESTAS REFLEXIONES HA QUEDADO CLARO que el gobernante no está de suyo en la mejor posición para abordar los dificilísimos asuntos que le plantean a una sociedad las cuestiones humanitarias. En efecto, el entrenamiento y la práctica del gobernante lo llevan a considerar de modo erróneo los problemas donde se hallan involucrados principios irrenunciables de lo humano, pues el gobernante los aborda en una perspectiva política, jurídica y administrativa, a la que tales problemas son recalcitrantes, con el efecto de que de ordinario la primera respuesta política resulta ser de rechazo del problema y de remisión a otra instancia. Si los sujetos involucrados en la cuestión humanitaria mantienen su posición o encuentran un apoyo efectivo 
ante el gobernante, será posible encontrar una salida a la dificultad. Lo que muestran tanto Esquilo como Eurípides es que la resolución de las cuestiones humanitarias es de tal índole que toda la sociedad va a verse involucrada en ellas por lo que solamente en el sistema democrático puede encontrarse el respaldo político suficiente y necesario para adoptar las exigentes soluciones que pide un conflicto humanitario. En ello, la tarea del gobernante es decisiva, pues no puede esperarse que la asamblea democrática asuma sin más el conflicto humanitario que toca a las puertas de la ciudad sin la persuasión, el ascendiente y el compromiso del gobernante. En la tragedia griega el costo político de estas decisiones es la guerra, que no debe tomarse en sentido literal, sino como figura de que la resolución de los asuntos humanitarios conlleva un costo grande para una sociedad. Incluso después de tomadas las decisiones, hay que darles tiempo para que en el orden cultural y social todos los involucrados vayan adaptando su comportamiento y sus actitudes a las nuevas realidades. No es algo que ocurra de la noche a la mañana ni como por milagro. De todos modos, las cuestiones humanitarias son insoslayables y, dada nuestra común humanidad, para su resolución no hay otro espacio que el ámbito de justicia, igualdad y equidad establecido por la democracia. Es en este sentido que la tragedia prueba la democracia. 


\section{Referencias}

Bakewell, G. (2014). Aeschylus: Suppliants. H.M. Roisman (Ed.), The Encyclopedia of Greek Tragedy. Vol. I (pp. 67-72). Malden MA/Oxford: Wiley/ Blackwell.

Chou, M. (2012). Greek Tragedy and Contemporary Democracy. New York/ London: Bloomsbury.

Esquilo. (2008). Persians. Seven against Thebes. Suppliants. Prometheus Bound. (Trad. A.H. Sommerstein). Cambridge, MA/London: Harvard University Press/ Loeb Classical Library.

Esquilo. (2001). Les suppliantes. Bardollet, L., Deforge, B. \& Villemonteix, J. (Eds.), Les Tragiques grecs (Vol. I). (Trad. L. Bardollet \& B. Deforge). Paris: Éditions Robert Laffont.

Esquilo. (1986). Tragedias. (Trad. B. Perea Morales). Madrid: Gredos.

EuRíPIDEs. (2001). Les suppliantes. B. Deforge \& F. Jouan (Eds.), Les Tragiques grecs (Vol. II). (Trad. H. Grégoire). Paris: Éditions Robert Laffont.

EuRíPIDES. (1998). Suppliant Women. Electra. Heracles. (Trad. D. Kovacs). Cambridge, MA/London: Cambridge, MA/London: Harvard University Press/ Loeb Classical Library.

Eurípides. (1978). Tragedias, Vol. II. (Trad. J.L. Calvo Martínez). Madrid: Gredos.

Grimal, P. (1981 [1951]). Diccionario de mitología griega y romana. (Trad. F. Payarols). Barcelona: Paidós.

Martin, T.R. (2000). Ancient Greece. From Prehistoric to Hellenistic Times. New Haven CT/London: Yale Nota Bene/Yale University Press.

Rhodes, P.J. (2014). Athenian Democracy and Tragedy. H.M. Roisman (Ed.), The Encyclopedia of Greek Tragedy, Vol. I (pp. 155-159). Malden MA/Oxford: Wiley/ Blackwell.

Roisman, H.M. (Ed.). (2014). The Encyclopedia of Greek Tragedy (Vol. I). Malden, MA/Oxford: Wiley/Blackwell.

Sommerstein, A.H. (2010). The Tangled Ways of Zeus and other Studies in and around Greek Tragedy. Oxford/New York: Oxford University Press.

Storey, I.C. (2014). Euripides: Suppliants. H.M. Roisman (Ed.), The Encyclopedia of Greek Tragedy (Vol. I, pp. 466-471). Malden MA/Oxford: Wiley/Blackwell. 